
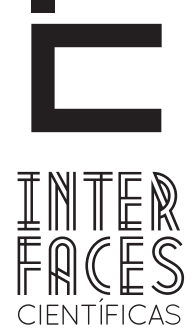

DIREITO

\title{
MULHERES NA JURISPRUDENCIA SERGIPANA: A DESEMBARGADORA CLARA LEITE EM SERGIPE E SUA TRAJETÓRIA
}

Janaina Cardoso de Mello ${ }^{1}$

\section{RESUMO}

Ao longo do século $X X$, as heranças de uma sociedade fundada no patriarcalismo do período colonial impregnou a sociedade brasileira, e particularmente a sergipana, de atitudes misóginas e restritivas ao exercício da profissão no espaço público por mulheres. Rompendo paradigmas, a desembargadora Clara Leite de Rezende tornou-se um exponencial de competência e luta no campo da Justiça. Primeira magistrada do Tribunal de Justiça do Estado de Sergipe assumiu todos os cargos jurídicos no Estado, mesmo quando a realidade estatística demonstrava que o quantitativo feminino no judiciário brasileiro ainda mantinha-se extremamente diminuto entre 1999 e 2003. Assim, o artigo apresenta a mulher, a esposa, a mãe e, sobretudo a magistrada, homenageada e inspiradora de novas gerações. Utiliza-se como metodologia de análise a biografia e o estudo de trajetórias.

\section{PALAVRAS-CHAVE}

Mulher. Justiça. Pioneirismo. Sergipe. Brasil. 


\section{ABSTRACT}

Throughout the 20th century, inheritance of a society based on patriarchy of colonial Brazilian society permeated, and particularly of Sergipe, of misogynistic attitudes and restrictive to the profession in the public space by women. Breaking paradigms, the associate judge Clara Leite de Rezende became an exponential of competence and struggle in the field of Justice. First magistrate of the Court of Justice of the State of Sergipe, assumed all legal positions in the State, even when the statistical reality showed that the female quantitative in Brazilian judiciary still remained extremely small between 1999 and 2003. Thus, the article presents the woman, wife, mother and especially the magistrate, honored and inspiring new generations. It is used as an analysis methodology and biography and the study of trajectories.

\section{KEYWORDS}

Woman. Justice. Pioneering. Sergipe. Brazil.

\section{RESUMEN}

A lo largo del siglo XX, los legados de una sociedad fundada en el patriarcado período colonial se impregnó la sociedad brasileña y particularmente la provincia de Sergipe, actitudes de repulsa y a la vez restrictivas, para el ejercicio de la profesión en el espacio público por las mujeres. Rompiendo paradigmas, la juez superior Clara Leite de Rezende, se convirtió en un exponencial de competencia y lucha en el campo de la justicia. Primer magistrado de la corte de justicia de la Provincia de Sergipe, asumió todas las posiciones legales en el estado, incluso cuando la realidad estadística demostró que la mujer en el poder judicial brasileño, cuantitativamente, seguía siendo extremadamente pequeña entre 1999 y 2003. Así, el artículo presenta la mujer, esposa, madre y especialmente al magistrado, homenajeado e inspirando a nuevas generaciones. Es utilizado como una metodología de análisis la biografía y el estudio de las trayectorias.

\section{PALABRAS CLAVE}

Mujer, Justicia, Pionero, Sergipe, Brasil. 


\section{INTRODUCÇÃO}

0 artigo em questão analisa a presença da muIher na jurisprudência sergipana a partir do papel desempenhado pela Desembargadora Clara Leite de Rezende. Parte-se do pressuposto de que apesar do conservadorismo da sociedade nas relações de gênero estabelecidas no meio judiciário, enquanto reflexo da própria sociedade patriarcal brasileira, algumas mulheres destacaram-se por seu pioneirismo, imprimindo as marcas de sua presença decisória na história do Direito em Sergipe.

A compreensão de como antigos paradigmas são quebrados com atuações individuais capazes de modificar um coletivo conduz a problemática dessa análise. No que tange aos estudos da participação feminina no judiciário sergipano ainda há um cenário escasso em termos de produção acadêmica, contribuindo para seu obscurantismo.

Como procedimento metodológico a pesquisa se norteou por dois eixos fundamentais: a biografia, compreendida como a coleta de dados em textos sobre indivíduos já estudados como objetos de reflexão narrativa e o estudo de trajetórias que permite gerar assertivas e considerações conclusivas a partir das informações obtidas (PASSERON, 1990).

Para a realização proposta recorreu-se às seletas com textos publicados por historiadores e advogados do judiciário sergipano, bem como se lançou mão de revistas e jornais com temática do judiciário. 0 cotejamento de vários olhares sobre a trajetória da Desembargadora Clara Leite de Rezende permite preencher as lacunas e focá-la sobre um prisma de possibilidades interpretativas revelando-a como uma mulher suscetível a distintas representações sociais.

\section{MULHERES NA JURISPRUDÊNCIA: ENTRE 0 CONSERVADORISMO E O PIONEIRISMO}

\author{
Aglutinadora, pacifista sem se permitir fraquezas, de- \\ senvolveu a arte de demolir, uma a uma, as muralhas \\ seculares com que o preconceito confinara as mu- \\ lheres nos guetos do atavismo cultural incontrastado \\ (MACHADO, 2010, p. 23).
}

Essa é a descrição honrosa com a qual o desembargador Netônio Bezerra Machado apresenta o perfil da primeira mulher a assumir o cargo de desembargadora do Tribunal de Justiça do Estado de Sergipe, no Brasil, em $1^{\circ}$ de novembro de 1984, Clara Leite de Rezende.

Antes dela, somente outra mulher sergipana havia obtido destaque na magistratura, Maria Rita Soares de Andrade (nascida em Aracaju-SE, em 1904) que concluiu o curso de Ciências Jurídicas na Faculdade de Direito da Bahia em 1926, tendo sido a primeira mulher a integrar o Conselho Federal da Ordem dos Advogados do Brasil e depois, em 1967, tornou-se a primeira juíza federal do Brasil.

Assim, escrever sobre a trajetória das mulheres que assumiram a magistratura brasileira como profissão implica percorrer um árduo caminho por uma sociedade conservadora, majoritariamente composta por homens de influência, que constituiu muitas barreiras à ascenção de mulheres que ousaram sair de casa para assumir na vida pública cargos de revelada competência.

Por isso, ao ressaltar uma das facetas desse patriarcalismo, as considerações peliminares sobre os dados parciais coletados entre 1999 e 2004 a respeito da participação da mulher na magistratura brasileira, em pesquisa organizada pelo Palácio do Planalto do Governo Federal Brasileiro, atestaram que:

À pouca representatividade de mulheres em espaços de poder e decisão chamamos de fenômeno da mascu- 
linização do comando e feminização da subalternidade. Esse fenômeno demonstra que, mesmo frente aos espaços conquistados pelas mulheres na sociedade, o poder de mando permanece fiel à lógica da cultura patriarcal. No judiciário, poder que espelha essa cultura, a participação de mulheres e homens também acontece de forma desigual. (MELLO et al, 2005, p. 2).

No Brasil, a primeira mulher a doutorar-se na área jurídica, em 1970, e que galgou o posto de professora da Faculdade de Direito da Universidade de
São Paulo foi a jurista Ada Pellegrini Grinover, embora tenha sido desestimulada a concorrer à vaga no Tribunal de Justiça de São Paulo, em razão de àquela instituição à época não possuir banheiro feminino (DEDA, 2010, p. 30).

Fatos como este muitas vezes terminam por interferir no quantitativo de mulheres que conseguem ascender no judiciário brasileiro nos séculos XX e XXI como as tabelas e gráficos abaixo podem demonstrar.

Tabela 1 - Percentual de Magistrados e Magistradas nas Justiças Comum, Federal e do Trabalho de $1^{\circ} \mathrm{Grau}$ (1999)

\begin{tabular}{|l|l|l|l|l|l|}
\hline Cargos Providos & Magistrados & Magistradas & Total & Magistrados (\%) & Magistradas (\%) \\
\hline Justiça Comum & 4.991 & 2.240 & 7.231 & 69,02 & 30,98 \\
\hline Justiça Federal & 535 & 224 & 759 & 70,49 & 29,51 \\
\hline $\begin{array}{l}\text { Justiça do Traba- } \\
\text { lho }\end{array}$ & 2.758 & 1.271 & 4.029 & 68,45 & 31,55 \\
\hline Total & 8.284 & 3.735 & 12.019 & 68,92 & 31,08 \\
\hline
\end{tabular}

Fonte: MELLO e outros autores, 2005.

A Tabela 1 expõe o grande diferencial por gênero no exercício da magistratura brasileira em 1999. As mulheres estão presentes em aproximadamente um terço dos cargos na Justiça Comum, na Justiça Federal e na Justiça do Trabalho. Os homens dominam o quantitativo em todas as instâncias observadas.

\section{Grafico 1}

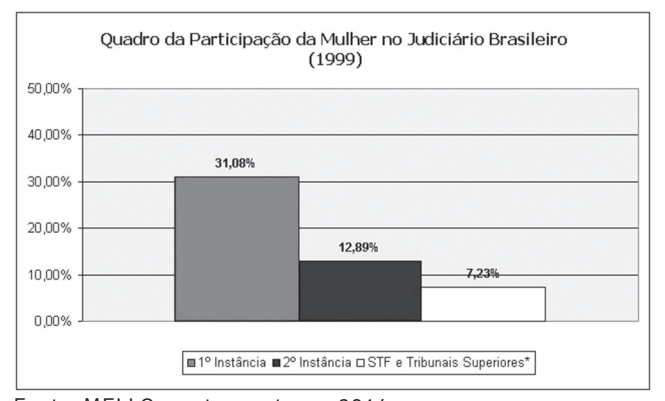

Fonte: MELLO e outros autores, 2014
O Grafico 1 apresenta a distribuição feminina nas instâncias do judiciário brasileiro e o que se pode examinar é um percentual cada vez mais baixo em relação ao grau de ascenção aos postos de importância no judiciário brasileiro em 1999.

\section{Grafico 2}

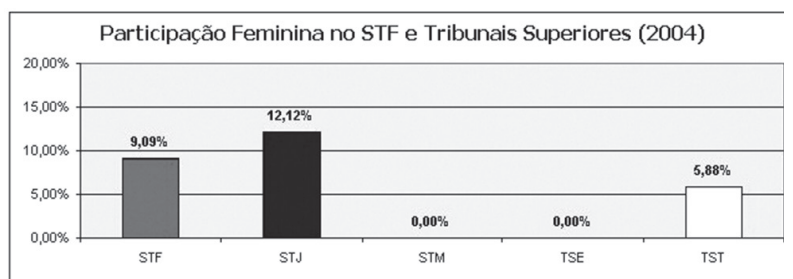

Fonte: MELLO e outros autores, 2005.

Já o Gráfico 2 explicita com maior acuidade o percentual detalhado de ocupação no Superior Tribunal 
Federal (STF), Superior Tribunal de Justiça (STJ), Superior Tribunal Militar (STM), Tibunal Superior Eleitoral e Tribunal Superior do Trabalho (TST). Verifica-se a ausência completa, em 2004, de mulheres no Superior Tribunal Militar (STM) e no Tibunal Superior Eleitoral (STE), sendo que nos demais tribunais a ocupação feminina não chega nem a $15 \%$.

Tabela 2 - Cargos Providos no Estado de Sergipe por gênero na Justiça Comum de $2^{a}$ instância (1999)

\begin{tabular}{|l|l|l|}
\hline Desembargadores & Desembargadoras & Total \\
\hline 08 & 02 & 10 \\
\hline
\end{tabular}

\begin{tabular}{|l|l|}
\hline Desembargadores (\%) & Desembargadores (\%) \\
\hline 80 & 20 \\
\hline
\end{tabular}

Fonte: Adaptação de MELLO e outros autores, 2005.

Diminuindo a escala da lupa de observação para ter como foco a presença feminina nos cargos do judiciário em Sergipe constata-se que o quantitativo de desembargadoras não alcança mais de $20 \%$ em 1999. Comparando-se com estados próximos como Bahia onde a ocupação masculina é de 26 homens para 4 mulheres; Alagoas com 11 homens para nenhuma mulher ou mesmo o Distrito Federal (Brasília) com 28 homens para 03 mulheres, conclui-se que o ocupação feminina no judiciário brasileiro é muito limitada e insuficiente.

Tabela 3 - Cargos Providos no Estado de Sergipe por gênero na Justiça Comum de $2^{\mathrm{a}}$ instância (2003)

\begin{tabular}{|l|l|l|}
\hline Desembargadores & Desembargadoras & Total \\
\hline 10 & 03 & 13 \\
\hline Desembargadores (\%) & Desembargadores (\%) & \\
\cline { 1 - 2 } 76,92 & 23,08 \\
\hline
\end{tabular}

Já em 2003, o quantitativo de desembargadoras em Sergipe subiu apenas 1 ponto, enquanto a ocupação masculina subiu 2 pontos no percentual. Comparativamente no Estado da Bahia houve um decrécimo de 19 homens para 8 mulheres com estas elevando em $50 \%$ o quantitativo anterior de sua participação na Justiça Comum; Alagoas com 10 homens para 1 mulher, aparecendo enfim a presença feminina como desembargadora e o Distrito Federal (Brasília) com 36 homens para 4 mulheres, revelando a amplicação em 10 pontos para os homens e a estagnação na ocupação por mulheres.

Por outro lado, a Revista VOCÊ S.A., na Edição $n^{0} 103$ de janeiro de 2007, baseada na pesquisa Stratégic Compensation Survey, realizada pela Consultoria Watson Wyatt do Estado de São Paulo com 134 empresas que empregam aproximadamente 450 mil pessoas relatou que $34 \%$ dos cargos de comando nos setores jurídicos de grandes empresas são ocupados por mulheres, como também as mulheres já são $42,3 \%$ do total de advogados do Brasil e 50,5 \% dos advogados formados com até cinco anos. Esses dados podem indicar que em razão da carreira junto ao judiciário governamental ser ainda restritiva, as mulheres da advocacia estão optando pela atuação jurídica nas empresas privadas onde sua aceitação tem sido mais ampla.

Todavia, na contramão dos impedimentos do caminho da Justiça Pública, mulheres como Clara Leite de Rezende conquistaram espaços de visibilidade, mantendo suas feições demasiadamente humanas, mas com profundo impacto no pêndulo da justiça. $E$ é desta trajetória que este artigo se proprõe a tratar, revelando suas nuances particulares e públicas por meio de relatos daqueles que conviveram com ela no cotidiano sergipano. 


\section{A MULHER DEMASIADA HUMANA EM SUA TRAJETÓRIA}

Nascida em 27 de junho de 1940, no Engenho Angico - na cidade de Riachuelo no Estado de Sergipe - Brasil, Clara Sampaio Leite ${ }^{2}$ chegou ao mundo como a décima segunda filha de Guiomar Sampaio Leite e Sílvio César Leite. Mais tarde, em seu discurso de posse como desembargadora, o legado familiar que recebera viria à tona:

Nasci em um lar exemplo de harmonia, dignidade e amor. Última de uma prole de doze filhos, havidos de dois consórcios, tive o acompanhamento de onze irmãos que desbravaram os caminhos da vida, legando-me uma trilha de exemplos dignificantes, cada um dentro de sua individualidade e potencialidades diversificadas. (MEDINA, 2010, p. 44).

Filha e sobrinha de médicos, irmã de engenheiros, professores, juristas e políticos, Clara Leite de Rezende cresceu em um ambiente de homens que transitavam pelo poder como se este fosse um exercício natural de suas potencialidades. Desse modo, a família Leite espalhou sua influência sobre Sergipe, sendo consagrada a nome de logradouros na capital Aracaju ao longo do século XX. Tal situação decorria do fato de culturalmente Sergipe conservar hábitos e tradições provincianas cuja valorização de famílias com sobrenomes, títulos e posses econômicas constituía marca indelével na História do patriarcado do Nordeste do Brasil ${ }^{3}$.

Órfã de pai aos três anos de idade viveu sua infância e adolescência no Bairro Industrial em Aracaju, de frente para o Rio Sergipe, de onde podia observar o contraste socioeconômico entre as famílias de elite em seus bangalôs bucólicos e o pulsante vai e vem de operários nas ruas, fábricas e bondes. Visão que coaduna como que atestam os documentos do Tribunal

2. Nome de solteira.

3. No Brasil, até meados do século XX, "A mulher era subjugada à condição de total submissão, ao ponto de juridicamente ser-lhe negada a capacidade absoluta. Era-lhe proibida a manifestação social, o estudo e o trabalho, sem o consentimento do pai ou do marido". Somente com a Lei 4.121, de 27 de agosto de 1962 que a mulher é considerada plenamente capaz (CACHAPUZ, 2004, p.71). do Arquivo Judiciário do Estado de Sergipe na visão de seus pesquisadores:

[...] podemos perceber do processo de urbanização da cidade de Aracaju nos autos judiciais [...] o cotidiano dos indivíduos, modelados mediante fortes esquemas de coação, para que formados sob os parâmetros sociais vigentes, possam cumprir seu papel de ser social. (NASCIMENTO, 2008, p. 1).

Sua formação inicial foi realizada no Colégio do Salvador e depois o ensino secundário foi cursado no Colégio Nossa Senhora de Lourdes, das Irmãs Sacramentistas. Seu curso científico concluiu no Colégio Atheneu (MEDINA, 2010, p. 43). Todos os estabelecimentos de ensino tradicional e acolhedores dos filhos da elite sergipana.

A tradição de renomados juristas de Sergipe como Tobias Barreto, Silvio Romero, Fausto Cardoso e Gumerssindo Bessa incentivaram a percepção por Daniel Campos e Maurício Graccho Cardoso da necessidade da criação de uma escola de estudos jurídicos em Sergipe. Mas somente em 1951 foi criada a Faculdade de Direito de Sergipe.

Por isso, diferentemente de sua antecessora sergipana no pioneirismo jurídico brasileiro, Maria de Rita Soares - que precisou cursar a Facauldade de Direito na Bahia - Clara Leite de Rezende diplomou-se pela Faculdade de Ciências Jurídicas e Sociais de Sergipe em 1962.

Durante seus estudos de Direito, Clara Leite participou da Juventude Universitária Católica (JUC) em Sergipe sob a conduçao de Dom José Vicente Távora e do Padre Luciano Duarte. Sobre esse período de sua vida afirmou:

Aprendi com ele a discernir valores, a objetivar metas, a proceder uma análise crítica do mundo, do meu trabalho e dos demais companheiros. Aprendemos todos a argumentar tecnicamente, a desenvolver a retórica muito importante nas conquistas universitárias. (MEDINA, 2010, p. 45). 
Valores, metas, análise crítica, argumentação técnica e domínio da retórica, qualidades essenciais ao ofício da magistratura. Aliada a essa formação não-formal estava seu gosto pela literatura francesa quer nas obras clássicas de Stendhal, Victor Hugo, Lamartine, Pascal ou Saint-Exuperry, mas também nos periódicos Paris Match, Le Figaro ou Elle et Lui (MEDINA, 2010, p. 46).

Antes mesmo de concluir seu bacharelado, aos dezoito anos, trabalhou na Legião Brasileira de Assistência - criada em 1942 pela primeira dama brasileira Darcy Vargas - no auxílio das famílias dos soldados que participaram da Segunda Guerra Mundial (MEDINA, 2010, p. 47).

Casou-se com Roberto Rezende, um Engenheiro Agrônomo, com quem teve dois filhos.

\section{A DESEMBARGADORA NO PÊNDULO DA JUSTIÇA SERGIPANA}

O Direito aplicado terá que representar, para a sociedade, a restauração do equilíbrio social rompido com as suas violações. Ao magistrado é dado refazer a lei, para que traduza o verdadeiro sentido desse direito (REZENDE apud CERQUEIRA, 2010, p. 225).

A trajetória de Clara Leite de Rezende até sua chegada a essa concepção do Direito perpassou distintos caminhos. Atuou como advogada de abril de 1963 até março de 1970, ao lado dos advogados Luiz Rabelo Leite e José Silvério Leite Fontes, inclusive no exercício do cargo de Membro do Conselho da Ordem dos Advogados do Brasil/secção de Sergipe. Em seu discurso de posse no Tribunal de Justiça do Estado de Sergipe ressaltou:

[...] o culto do Direito empolgava-me nas alocuções saudosas dos professores valorosos que integravam o Corpo Docente do curso jurídico e que deixaram profundas marcas nas gerações que tiveram ensejo de ouvi-los. 0 contato com o trabalho assistencial des- pertava-me para a aplicação real desse direito e impulsionava-me para o exercício da advocacia, onde tive a grata felicidade de integrar, durante alguns anos, uma equipe de profissionais com os então advogados Luiz Rabelo Leite e José Silvério Leite Fontes. (REZENDE, 1984, p. 200-201).

Todavia, em 19 de março de 1970, ingressou na magistratura do Estado de Sergipe servindo às comarcas de Nossa Senhora da Glória (1970-1972), Frei Paulo (1972-1975), Estância (1975-1977) e Aracaju (1977-1984) (DEDA, 2010, p. 31).

\section{[...] com o ingresso na Magistratura, desafiada a convi- ver, na prática, com situações conflituais que iam des- de a desconfiança dos jurisdicionados na capacidade técnica e na experiência de vida de qualquer mulher para judicar, até um certo sentimento machista de inferioridade ante a submissão ao seu comando. (MA- CHADO, 2010, p. 24).}

A vida profissional no judiciário do interior do Estado intervinha na vida pessoal como afirmou a própria desembargadora Clara Leite de Rezende: "Trabalhar em uma cidade longe da minha família foi um dos grandes desafios até então porque eu já estava casada, tinha filhos, e eles moravam aqui em Aracaju" (INFONET, 2008).

Vários desafios se apresentaram a Clara Leite de Rezende cuja atuação, também, foi efetiva na Corregedoria Geral da Justiça entre 1987 e 1989, bem como Presidente do Tribunal Regional Eleitoral (1991-1993) e Presidente do Tribunal de Justiça do Estado de Sergipe no período de 1995 a 1997 (MACHADO, 2010, p. 25).

Na presidência do Tribunal, Clara Leite de Rezende enveredou pela construção de fóruns (nos municípios de Riachuelo, Cristinápolis, Estância, latabaiana, Pinhão e Aracaju), reformulação e modernização administrativa do judiciário sergipano.

A grandiosidade do Fórum Gumersindo Bessa por si só justificaria todos os aplausos à sua gestão, pela complexidade da obra, que integra o atendimento a 
inúmeras atividades e finalidades da Justiça, e pelo seu simbolismo administrativo, fruto de uma realidade predominante no Estado de Sergipe, a independência e harmonia entre os Poderes. (CARVALHO, 2010, p. 34).

O Fórum Gumersindo Bessa, localizado na cidade de Aracaju em Sergipe, é um dos maiores espaços dedicados aos serviços judiciários no Nordeste do Brasil. Além de todo o aparato administrativo, possui também um Arquivo responsável pelo acondicionamento e restauro de documentos que compreendem desde fontes históricas compostas por processos dos séculos XVIII e XIX, bem como os arquivos correntes manuseados pelos profissionais do judiciário na contemporaneidade.

Apesar de sua atuação na chefia de instituição jurídicas em Sergipe, não descuidou da atualização de seus conhecimentos jurídicos, participando de cursos e eventos jurídicos nacionais e internacionais (DEDA, 2010, p. 31). Fez pós-graduação em Política e Estratégia, pela Escola Superior de Guerra, em 1988, e cursos de extensão em Direito Criminal, pela Universidade de Nova lorque, Direito Comparado, pela Universidade da Cidade do México e Direito Comunitário, pela Universidade de Sorbonne, na França.

O contato com os estudos tornou-a preocupada com a fomação continuada dos juristas, por isso a desembargadora Clara Leite de Rezende assumiu por mais de uma vez a direção da Escola Superior da Magistratura de Sergipe (ESMESE): “[...] defendendo posições muito firmes do valor do aperfeiçoamento, dos cursos complementares, do aprimoramento de uma ética voltada para os jurisdicionados" (MEDINA, 2010, p. 47).

Conforme as próprias palavras da desembargadora Clara Leite de Rezende, quando na $15^{a}$ Sessão Ordinária do Tribunal Pleno, em 21 de maio de 2003, no $8^{\circ}$ andar do Palácio da Justiça Tobias Barreto de Menezes, foi reeleita para mais um biênio na direção da ESMESE: “Não há mais espaços para juízes improvisados. A sociedade não quer mais pagar esse preço. A escola da magistratura vai se engajar nesse programa e mergulhar fundo na formação de seus novos juízes" (TRIBUNAL DO JUDICIÁRIO DO ESTADO DE SERGIPE, 2003, p. 3).

Em sua gestão anterior da Esmese, assumida em maio de 2001, a desembargadora Clara Leite de Rezende empenhou-se em ações que impulsionaram a otimização dos serviços prestados pela equipe da escola. No plano organizacional, o investimento em novas tecnologias da informação resultou na criação da página da escola na Internet e no Serviço de Atendimento ao Aluno (SAAluno). No aspecto estrutural, a nova sede da Esmese, no $7^{\circ}$ andar do Anexo Administrativo Governador Albano Franco, representou uma das grandes conquistas da administração em continuidade com o trabalho dos ex-diretores da escola (TRIBUNAL DO JUDICIÁRIO DO ESTADO DE SERGIPE, 2003, p. 3).

Por fazer história no judiciário sergipano o reconhecimento por seus feitos não tardou, assim, Clara Leite de Rezende foi convidada a ingressar na Academia Sergipana de Letras (BARRETO, 2010, p. 39-40), sendo notícia de mais um número do Jornal da Esmese que anunciou:

Foi empossada, em 26 de novembro de 2004, em sessão solene da Academia Sergipana de Letras (ASL), realizada no auditório do Palácio da Justiça de Sergipe, a Desembargadora Clara Leite de Rezende, que passa a ocupar a cadeira $n^{0} 7$, que tem como patronoo romancista Ranulfo Prata e já foi ocupada por Manuel Curvelo de Mendonça e por Luiz Pereira de Melo. (TRIBUNAL DO JUDICIÁRIO DO ESTADO DE SERGIPE, 2004, p. 3).

Na ocasião, a desembargadora Clara Leite de Rezende foi agraciada com a Comenda do Mérito Cultural Sílvio Romero, além de ser exaltada pelo colega, também jurista sergipano, na época ministro do Supremo Tribunal Federal (STF), Carlos Augusto Ayres de Freitas Britto que assinalou:

É uma literata. Nos votos que produz, nas sentenças que escreveu, nos artigos jurídicos, nas aulas e confe- 
rências que tem proferido, ela revela aquilo que é próprio do literato: uma visão de conjunto, uma maneira muito personalizada de escrever, muita beleza quando fala, quando escreve, ela só vem a enriquecer a ASL, é uma presença muito saudada. (TRIBUNAL DO JUDICIÁRIO DO ESTADO DE SERGIPE, 2004, p. 3).

Antes, já havia recebido a Medalha do Mérito Serigy, em grau de Comendador, outorgada pelo Município de Aracaju, em 1973 e o Colar do Mérito Tobias Barreto, outorgado pelo Ministério Público do Estado de Sergipe.

No dia 8 de março de 2010 foi homenageada pela Prefeitura de Aracaju, por meio da Secretaria Municipal de Assistência Social e Cidadania (Semasc), na $6^{a}$ edição do Trofeu Núbia Marques ${ }^{4}$, no salão de festas da Associação de Engenheiros Agrônomos de Sergipe (Aease), recebendo o trofeu confeccionado pela artista plástica Lânia Duarte, agraciada com o prêmio no ano de 2005. Entrevistada durante a premiação, Clara Leite de Rezende declarou: "Núbia era corajosa, enfrentou os preconceitos de sua época, ela muito merecia que seu nome fosse dado a esse prêmio e eu me senti muito honrada em recebê-lo".

Em virtude da reforma da jurista, ainda em 2010, o Tribunal de Justiça de Sergipe e a Escola Superior da Magistratura de Sergipe inauguraram o "Espaço Sociocultural Desembargadora Clara Leite de Rezende". Situado no $8^{\circ}$ andar do anexo administrativo Desembargador Antonio Góis, o espaço foi dedicado a cultura, entretenimento, leitura e arte (NE/DIREITO, 2010).

Após a inauguração do Espaço, os convidados participaram de um coquetel e da abertura da Exposição "Ser grata é ser justa”, que faz uma viagem pela trajetória da Desembargadora Clara Leite de Rezende e foi organizada pela equipe do Memorial do Judiciário

4. O troféu Núbia Marques (professora e escritora) surgiu em 2005 e é entregue a mulheres de destaque na sociedade sergipana, que estão a contribuir em diversas áreas, seja na literatura, na arte, na educação. A premiação faz parte das comemorações aos 155 anos de Aracaju e ao Dia Internacional da Mulher. do Estado de Sergipe. A exposição reuniu fotos, peças documentais, discursos, medalhas, troféus e placas comemorativas de grande significado na vida da magistrada (NE/DIREITO, 2010).

Para Renata Mascarenhas, diretora do Memorial do Judiciário, a exposição trata de “momentos da vida da desembargadora, retratados por meio de fotografias, que ilustram, ora sua trajetória na Justiça sergipana, ora a esposa, a sogra, a mãe e a avó dedicada" (NE/DIREITO, 2010).

\section{CONCLUSÃO}

Apesar dos entraves da sociedade brasileira no que dizem respeito à ascensão das mulheres no campo profissional, algumas impuseram suas vontades contra os preconceitos vigentes e ocuparam cargos de destaque e poder. É claro que em grande medida esse "empoderamento" nas relações de gênero, em seu início, vinha acompanhado de uma família com posses, mas que permitia à suas filhas ou esposas o acesso a um mundo diferenciado, marcado pela trajetória de ditos "grandes homens".

Mulheres como Clara Leite de Rezente, obtiveram oportunidades na magistratura que muitas outras sergipanas não conheceram ao longo de suas vidas. Incluindo algumas mulheres de elite que mesmo após graduarem-se permaneceram no íntimo do lar somente como esposas e mães.

Por isso, mesmo ainda compondo um universo quantitativo pequeno e privilegiado, a atuação desta jurista desde sua formação, com participação em associações voltadas para políticas sociais e depois seu ingresso na carreira jurídica estatal em Sergipe, assumindo cargos, preocupando-se com a formação complementar de juízes, sendo agraciada com medalhas, espaços culturais e exposições, fez de sua trajetória uma inspiração para as novas gerações de mulheres afeitas ao bacharelado em Direito. 
A mudança cultural nas sociedades é lenta, pois envolve uma mudança de mentalidade e requer vontade e inciativa, envolta em tensões, conflitos e pioneirismos. A desembargadora Clara Leite de Rezende tem um papel significativo na história da jurisprudência brasileira e rememorar esse percurso permite refletir sobre o que ainda carece ser mudado para que se possam ampliar as conquistas femininas no decorrer desse longo século XXI.

\section{REFERÊNCIAS}

BARRETO, Luiz Antonio. Clara Leite de Rezende e a tradição cultural do judiciário, In: CERQUEIRA, Rafael Santa Rosa (coord.) Seleta do Memorial do Poder Judiciário do Estado de Sergipe. Escritos em homenagem à Desembargadora Clara Leite de Rezende, (1). Aracaju: Nossa Gráfica, 2010, p.37-40.

CACHAPUZ, Rozane da Rosa. Da família patriarcal à família contemporânea. Revista Jurídica Cesumar, 4, (1), 2004, p.69-77.

CARVALHO, José Nolasco de. Desembargadora Clara Leite de Rezende. In: CERQUEIRA, Rafael Santa Rosa (coord.) Seleta do Memorial do Poder Judiciário do Estado de Sergipe. Escritos em homenagem à Desembargadora Clara Leite de Rezende, (1). Aracaju: Nossa Gráfica, 2010, p.33-35.

CERQUEIRA, Rafael Santa Rosa (coord.) Seleta do Memorial do Poder Judiciário do Estado de Sergipe. Escritos em homenagem à Desembargadora Clara Leite de Rezende, (1). Aracaju: Nossa Gráfica, 2010, 280p.

DEDA, Artur Oscar de Oliveira. A mulher na magistratura: duas referências sergipanas. In: CERQUEIRA, Rafael Santa Rosa (coord.) Seleta do Memorial do Poder Judiciário do Estado de Sergipe. Escritos em homenagem à Desembargadora Clara Leite de Rezende, (1). Aracaju: Nossa Gráfica, 2010, p.29-32.
INFONET. Dra Clara Leite Rezende, primeira Desembargadora do Estado em Sergipe, 2008. Disponível em: <http://www.infonet.com.br/cidade/ler. asp?id=70978\&titulo=especial $>$. Acesso em: 30 jan. 2014

MACHADO, Netônio Bezerra. Referência Gratulatória. In: CERQUEIRA, Rafael Santa Rosa (coord.) Seleta do Memorial do Poder Judiciário do Estado de Sergipe. Escritos em homenagem à Desembargadora Clara Leite de Rezende, (1). Aracaju: Nossa Gráfica, 2010, p.21-27.

MEDINA, Ana Maria Fonseca. Relevância cultural da desembargadora Clara Leite de Rezende. In: CERQUEIRA, Rafael Santa Rosa (coord.) Seleta do Memorial do Poder Judiciário do Estado de Sergipe. Escritos em homenagem à Desembargadora Clara Leite de Rezende, (1). Aracaju: Nossa Gráfica, 2010, p.41-50.

MELLO, Mônica de et al. A participação da mulher na magistratura brasileira (considerações a respeito de dados parciais de 1999 a 2004). Revista Jurídica Virtual, 6, (70), 2005. Disponível em: <http://www. planalto.gov.br/ccivil_03/revista/Rev_70/artigos/ Art_Monica.htm>. Acesso em: 30 jan. 2014.

NASCIMENTO, Jorge Carvalho do. A Cidade no Arquivo: o Acervo do Poder Judiciário como fonte para os estudos da História de Aracaju. Revista eletrônica do Arquivo Judiciário - História, Memória e Justiça, 1, (1), 2008. pp. 1-16. Disponível em: <http://www.tjse. jus.br/revistahmj//images/stories/file/Artigo\%20-\%20Prof_Jorge.pdf>. Acesso em: 30 jan. 2014.

NE/DIREITO. TJ/SE e Esmese inauguram Espaço Sociocultural Desembargadora Clara Leite, 2010. Disponivel em: <http://www.nenoticias.com. br/61639_tise-e-esmese-inauguram-espaco-sociocultural-desembargadora-clara-leite.html>. Acesso em: 30. Jan. 2014.

PASSERON, J.C. Biographies, flux, itinéraires, trajectoires. Revue française de sociologie 31(1), 1990, p.3-22. 
PREFEITURA MUNICIPAL DE ARACAJU. Mulheres são homenageadas com Troféu Núbia Marques, 2010. Disponívelem:<http://http://www.aracaju.se.gov.br/trabalho_e_ renda/index.php?act=leitura\&codigo $=40752>$. Acesso em: 30 jan. 2014.

REZENDE, Clara leite de. Discurso. Revista do Tribunal de Justiça do Estado de Sergipe, 6, 1984, p.200-201. REVISTA VOCÊ S.A., n.103, de janeiro, 2007.
TRIBUNAL DO JUDICIÁRIO DO ESTADO DE SERGIPE. Desembargadora Clara Leite de Rezende administra a Esmese por mais dois anos (Entrevista). Jornal da Escola Superior da Magistratura de Sergipe, v.24, 2003, p.1-6.

TRIBUNAL DO JUDICIÁRIO DO ESTADO DE SERGIPE, Desembargadora Clara Leite de Rezende toma posse na Academia Sergipana de Letras. Jornal da Escola Superior da Magistratura de Sergipe, v.32, 2004, p.1-6. 